\title{
Traumatic optic neuropathy in head injury
}

\author{
Nishtha Yadav ${ }^{1}$, Renu Dhasmana ${ }^{2 *}$, Neeti Gupta ${ }^{3}$, Ranjit Kumar ${ }^{4}$ \\ ${ }^{\mathbf{1}}$ Senior Resident, ${ }^{2}$ Professor and Head, ${ }^{\mathbf{3}, 4}$ Associate Professor, ${ }^{\mathbf{1 - 3}}$ Dept. of Ophthalmology, ${ }^{\mathbf{4}}$ Dept. of Neuro Surgery, ${ }^{\mathbf{1 , 2 , 4}}$ Swami Rama \\ Himalayan University, Dehradun, Uttarakhand, ${ }^{3}$ All India Institute of Medical Sciences, Rishikesh, Uttarakhand, India
}

\section{*Corresponding Author: Renu Dhasmana}

Email: renudhasmana@gmail.com

\begin{abstract}
Introduction: Head injury accounts for approximately $3.4 \%$ of all emergency presentations. The role of ocular injuries secondary to head trauma in the causation of blindness continues to be an immense public health problem. This study is aimed to estimate the incidence of traumatic optic neuropathy, to obtain demographic data and to document concurrent injuries in cases of head injury.

Materials and Methods: A total of 510 patients presenting with head injury were examined for all the ocular injuries. Severity of head injury which was graded according to Glasgow Coma Scale (GCS). Computed tomography (CT) scan of head was done in all the patients. Visually evoked potential (VEP) was done in patients who had relative afferent pupillary defect (RAPD) and defective color vision. Diagnosis of traumatic optic neuropathy was confirmed on the basis of VEP.

Results: Majority of the people affected were males (77.5\%). Patients between 16-45 years were affected most. The most frequent site of injury was roadside $(72.55 \%)$. Ophthalmic involvement was observed in 313 individuals $(61.4 \%)$. Abnormal uni-ocular color vision was found in $21(4.11 \%)$ patients. RAPD was found in $24(4.70 \%)$ patients. VEP was abnormal in $10(1.96 \%)$ patients, of all the cases of head injury.

Conclusion: There was a $1.96 \%$ incidence of traumatic optic neuropathy in patients of head injury. Among all the ocular findings, eyelid ecchymosis with edema was most common. Intracranial hemorrhage was the most common CT scan finding in head injury patients. Chances of ophthalmic manifestations are much more when there is intracranial bleeding and facial fractures.
\end{abstract}

Keywords: Traumatic optic neuropathy, Head injury.

\section{Introduction}

Head injury accounts for approximately $3.4 \%$ of all emergency presentations. ${ }^{1}$ Upto $84 \%$ ocular involvement has been reported in head injury. ${ }^{2}$ The immediate impact of head injuries threatening other vital organs is so compelling that damage to the visual system is often ignored. ${ }^{3}$ Injuries in the optic nerve following trauma can be of two types, direct and indirect. Indirect injuries result from concussive forces which are transmitted to the optic nerve as a result of cranial or orbito-facial trauma. ${ }^{4}$ The bony optic canal is the most common site of optic nerve injury, referred to as an intracanalicular injury. The next common site is the intracranial optic nerve. Indirect damage is the most common cause of traumatic optic neuropathy and occurs in 0.5 to $5 \%$ of all closed head trauma cases. ${ }^{5}$ Direct injuries are open injuries where an external object penetrates the tissues and damages the optic nerve. However, it does not occur at the same frequency as indirect optic neuropathy. ${ }^{6}$ Commonly, patients with traumatic optic neuropathy have vision that is $20 / 400$ or less in the affected eye. However, the clinician must maintain a high index of suspicion to avoid missing more subtle cases of traumatic optic neuropathy. ${ }^{4}$ Comparative data from International Optic Nerve Trauma Study (IONTS) show that neither corticosteroid therapy nor optic nerve decompression are gold standard treatment of traumatic optic neuropathy. ${ }^{7}$ However Cook et al (1996) in a metanalysis reported that recovery of vision in patients treated with megadosage steroids or surgical decompression of the optic nerve was significantly better than those receiving no treatment. ${ }^{8}$

Proper assessment of ocular damage and early initiation of treatment after the injury has an important effect on the final outcome. Therefore, early diagnosis is imperative to prevent visual morbidity caused by trauma. This study is aimed to estimate the incidence of traumatic optic neuropathy, to obtain demographic data and to document concurrent injuries in cases of head injury.

\section{Materials and Methods}

This cross sectional and observational study was done at a tertiary care center of North India after getting approval from the institute's ethics committee. All new patients who were more than 5 years of age and presented with head injury were included in the study. Patients with known case of any intracranial pathology, pre-existing ocular abnormalities that might affect assessment of visual function, previous history of any intracranial surgery, and patients with history of prolonged drug intake affecting optic nerve function were excluded from this study.

Patients presented to the emergency department, were first stabilized and the Glasgow Coma Scale (GCS) was recorded in all cases. Classification of severity of head injury was done by using GCS scoring system. GCS of 1315 was classified as mild head injury, 9-12 as moderate head injury and 3-8 as severe head injury. A detailed history was obtained from all patients or from relative if patient was unconscious. Visual acuity was noted in all stable patients who were conscious and well oriented to time, place and person and was converted to logMar units. Bedside vision was noted in all immobile patients who were conscious and oriented. Color vision was checked bedside with ischihara chart with best corrected visual acuity for near.

A thorough clinical examination was undertaken with a torch light and slit lamp to examine the anterior segment. 
The fundus examination was done bedside with the use of indirect ophthalmoscope. Computed Tomography (CT) of all patients of head injury was done in which, firstly a tomogram was done and then scans were taken from base of skull to vertex. Visually evoked potential (VEP) of patients who had relative afferent pupillary defect (RAPD) with color vision defect was done. VEP reporting was done by a neurophysician. All cases of optic neuropathy were confirmed by an abnormal VEP.

\section{Results}

A total of 510 patients of head injury were studied. Patients between 16-45 years were affected most (61.56\%), with mean age of $33.1 \pm 17.7$ years. Majority of the people affected were males $(77.5 \%)$ with a male: female ratio of 3.4:1. Most of the patients presented within first 6 hours of head injury $(51.76 \%)$. Most patients had a mild head injury $(60.39 \%)$ according to GCS score. Moderate head injury was seen in $14.9 \%$ whereas severe head injury was noted in $24.7 \%$ patients. It was observed in our study that there was significant statistical association of ocular trauma with severity of head injury $(\mathrm{p}=0.04)$. Incidence of traumatic optic neuropathy was found to be $1.96 \%(n=10)$. No patients were found to have direct optic nerve injury. Of all the patients with optic nerve injury, only 1 patient had severe head injury, 4 had moderate and 5 had mild head injury.
Most common location of injury was roadside $(72.55 \%)$. Table 1 shows the location of injury.

Ophthalmic involvement was seen in 313 individuals $(61.4 \%)$. Visual acuity and color vision was obtained in 335 $(65.69 \%)$ patients who were conscious and oriented to time, place and person. The mean presenting visual acuity was $0.32 \pm 0.41 \log$ MAR units. Abnormal uni-ocular color vision was found in $21(4.11 \%)$ patients. No patient had binocular color vision defect.

Optic nerve involvement was seen in 30 (7.99\%) patients. No patients in the present study had an avulsed optic nerve.

Table 3 and 4 describe the pupillary and optic disc findings in patients of head injury. RAPD was found in 24 $(4.70 \%)$ patients. VEP was abnormal in $10(1.96 \%)$ patients, among all the cases of head injury.

Table 1: Location of site of trauma

\begin{tabular}{|c|c|c|}
\hline Location & Frequency $(\mathbf{n = 5 1 0})$ & Percentage \\
\hline Home & 80 & 15.68 \\
\hline Roadside & 370 & 72.55 \\
\hline School & 17 & 3.33 \\
\hline Workplace & 26 & 5.10 \\
\hline Other areas & 17 & 3.33 \\
\hline Total & 510 & 100 \\
\hline
\end{tabular}

Table 2: Incidence of Traumatic optic neuropathy according to severity of head injury (total number of patients, $\mathrm{n}=510$ )

\begin{tabular}{|l|c|c|}
\hline Type of injury & $\begin{array}{c}\text { Patients with ocular injury } \\
(\mathbf{n = 3 1 3})\end{array}$ & $\begin{array}{c}\text { Patients with optic neuropathy } \\
(\mathbf{n = 1 0})\end{array}$ \\
\hline Mild (GCS 13-15) & 171 & 5 \\
\hline Moderate (GCS 9-12) & 57 & 4 \\
\hline Severe (GCS 3-8) & 85 & 1 \\
\hline
\end{tabular}

Table 3: Pupillary involvement in the study group

\begin{tabular}{|c|c|c|c|}
\hline \multirow{2}{*}{\multicolumn{2}{|c|}{ 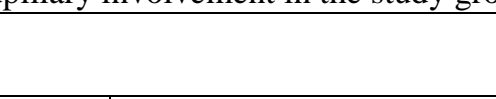 }} & Right eye $(n=313)$ & Left eye $(n=313)$ \\
\hline & & Frequency (\%) & Frequency $(\%)$ \\
\hline \multirow[t]{4}{*}{ Pupil } & RAPD & $13(4.15 \%)$ & $11(3.51 \%)$ \\
\hline & Fixed dilated pupil & $14(4.47 \%)$ & $12(3.83 \%)$ \\
\hline & Traumatic mydriasis & $4(1.28 \%)$ & $10(3.19 \%)$ \\
\hline & Sluggish reaction & $54(17.25 \%)$ & $52(16.61 \%)$ \\
\hline
\end{tabular}

Table 4: Optic disc findings in the study group

\begin{tabular}{|c|c|c|c|}
\hline & Right Eye $(n=313)$ & Left Eye $(n=313)$ \\
\hline & & Number $(\%)$ & Number (\%) \\
\hline \multirow[t]{3}{*}{ Optic Disc } & Papilledema & $1(0.32 \%)$ & $1(0.32 \%)$ \\
\hline & Disc pallor & $9(2.87 \%)$ & $6(1.91 \%)$ \\
\hline & Others & $5(1.60 \%)$ & $8(2.55 \%)$ \\
\hline
\end{tabular}

Table 5: Shows comparison between those without and with intracranial haemorrhage

\begin{tabular}{|l|c|c|c|}
\hline Variable** & NO Haemorrhage $(\mathbf{n = 2 3 4})$ & Intracranial Haemorrhage $(\mathbf{n = 2 7 6})$ & P \\
\hline GCS score & $13.4 \pm 2.9$ & $10.6 \pm 4.3$ & $<0.001$ \\
\hline Presenting Vision & $0.26 \pm 0.4$ & $0.38 \pm 0.4$ & 0.003 \\
\hline Pupil abnormality & $25(10.68 \%)$ & $60(21.73 \%)$ & 0.001 \\
\hline Optic disc abnormalities & $8(3.41 \%)$ & $8(2.89 \%)$ & 0.86 \\
\hline
\end{tabular}

** Ophthalmic manifestations are from right eye. No differences were found when findings from the left eye was considered as well 
On multivariable regression analysis adjusting for mode of injury, those with intracranial haemorrhage had a $66 \%$ higher likelihood (Odds ratio=1.66, 95\% CI $=1.2-2.4$, $\mathrm{p}=0.006$ ) of having ocular involvement of some form compared to those without the intracranial haemorrhage. (Table 5)

No significant association was found between optic nerve injury and severity of head injury.

\section{Discussion}

Ocular trauma refers to any injury to the eye. The role of ocular injuries secondary to head trauma in the causation of blindness continues to be an immense public health problem. The damage to the visual system is often ignored in cases of head injury due to injury to other vital organs. Consequently, the socioeconomic impact of ocular trauma can hardly be overestimated as those affected often have to face loss of career opportunities, major lifestyle changes and occasionally permanent physical disfigurement. ${ }^{3}$

In this study, the most common age group was 16-25 years $(29.15 \%)$, among which most of the patients were males $(77.5 \%)$ and the most frequent site of injury noted was roadside $(72.55 \%)$. This trend was thought to be due to activeness of the young adult in production activities which, in one way or the other exposes them to trauma related to transportation or their activities. This is also the group that commonly involve in social activities such as drinking which may further expose them to accidents due to reckless driving and assault.

In the present study, ophthalmic involvement was observed in $61.4 \%$ patients. This can be due to direct or indirect injury to the globe by counter coup mechanism, injury to visual cortex or due to trauma to the second, third, fourth, fifth or the sixth cranial nerve. Similar findings were observed in studies conducted by Faith et al and Stanslaus in which ocular involvement was seen in $68.7 \%$ and $65.6 \%$ cases respectively. ${ }^{9,10}$

Pupillary signs are of grave importance in indicating the site and severity of injury and in the prognosis of head injury. Pupillary abnormalities may be due to direct injury to the iris, optic nerve injury or due to central lesions. Presence of RAPD signifies optic nerve involvement. In the current study, RAPD was seen in $4.7 \%$ of all the cases of head injury. In study done by Faith et al pupillary abnormalities were seen in $21.7 \%$ patients of head injury and in another study done by Smruthi et al pupillary involvement was in $19 \%$ of cases of head injury. ${ }^{9,11}$

Clinical diagnosis of optic neuropathy can be made on the basis of color vision defect, RAPD and abnormal VEP in the same eye. In the present study, abnormal color vision was seen in $21(4.11 \%)$ patients. RAPD was present in all the patients with color vision defect indicating optic neuropathy. The diagnosis of traumatic optic neuropathy was confirmed by abnormal VEP. In the present study, 10 of total 510 patients of head injury had an abnormal VEP. Incidence of traumatic optic neuropathy was found to be $1.96 \%$. In a study done by Pakalpati et al $1.88 \%$ patients of head injury had traumatic optic neuropathy. Malik et al in their study showed $1.58 \%$ incidence of traumatic optic neuropathy in closed head injury patients. ${ }^{12,13}$

On comparing those with and without intracranial haemorrhage, it was found that those with intracranial haemorrhage had significantly lower GCS score and lower presenting vision compared to those with no intracranial haemorrhage. The lower vision was attributable to greater ocular involvement, greater extra ocular muscle restriction due to cranial nerve palsy, greater lid involvement and greater pupillary abnormalities.

\section{Conclusion}

The incidence of traumatic optic neuropathy in patients of head injury was $1.96 \%$ in the current study. It is recommended that all patients of head trauma must undergo ophthalmic examination.

Limitation of our study was that VEP of all patients could not be done.

\section{Conflict of Interest: None.}

\section{References}

1. Williams Norman S, Bulstrode Christopher JK, O’Connell P. Ronan. Head Injury. In: Bailey \& Love's short practice of surgery. $25^{\text {th }}$ ed. London (U.K.): Hodder Arnold; 2008. p. 299.

2. Dhaliwal A, West AL, Trobe JD, Musch DC. Third, Fourth and sixth cranial nerve palsies following closed head injury. $J$ Neuroophthalmol 2006;26(1):4-10.

3. Emen A, Uwemdimbuk E. Prevalence of traumatic ocular injuries in a teaching hospital south Nigeria 2 year study. Adv Trop Med Public Health Int 2012;2(3):102-8.

4. Miller Neil. R., Newman Nancy J., Biousse Valerie, Kerrison John B. Traumatic Optic Neuropathies. In. Walsh and Hoyt's Clinical Neuro-Ophthalmology: THE ESSENTIALS. $2^{\text {nd }}$ ed. Philadelphia (U.S.A.): Lippincott Williams \& Wilkins; 2008. p. 195-200.

5. Hathiram B, Khattar V, Rode S. Traumatic Optic Neuropathy. Otorhinolaryngol Clin - An Int J 2011;3:188-96.

6. Kenneth D., Steinsapir \& Robert A. Goldberg. Traumatic Optic Neuropathies. In. Walsh and Hoyt's Clinical NeuroOphthalmology: THE ESSENTIALS. $2^{\text {nd }}$ ed. Philadelphia (U.S.A.): Lippincott Williams \& Wilkins; 2008.p.431.

7. Hathiram BT, Khattar VS, Sonawane HP, Watve PJ. Traumatic Optic Neuropathy. Our Experience. Indian J Otolaryngol Head Neck Surg 2010;62(3):229-35.

8. Cook MW, Levin LA, Joseph MP, Pinczower EF. Traumatic optic neuropathy-A metanalysis. Arch Otolaryngol Head Neck Surg 1996;122:389-92.

9. Faith M, Githinji KJ, Sheila M, Margaret N. Ocular findings in patients with head injury. Int J Med Clin Sci 2014;1(2):9-17.

10. Stanslaus J. Ocular Trauma among Head Injury Patients. Available from URL: http://hdl.handle.net/123456789/1017. Accessed on Aug 15, 2017.

11. Smruthi, Hatti AS. Ocular Manifestations in Head Injury at SSIMS \& RC. Int J Sci Res 2013;4(2):2385-88.

12. Pakalapati P, Mohamad A, Sritej T. Ocular manifestations of head injury a clinical study. Indian J Appl Res 2017;5(6):479-82.

13. Malik A, Gupta A, Luthra N, Gupta V. Ocular manifestations of head injury: A clinical study. Sudanese J Ophthalmol 2016;8(2):46-50

How to cite this article: Yadav N, Dhasmana R, Gupta N, Kumar R. Traumatic optic neuropathy in head injury. Int $J$ Ocul Oncol Oculoplasty 2019;5(2):73-5. 